\title{
The short version of the Metacognitive Prospective Memory Inventory (MPMI-s): factor structure, reliability, validity, and reference data
}

\author{
Jan Rummel ${ }^{1 *}$ D, Daniel Danner ${ }^{2}$ and Beatrice G. Kuhlmann ${ }^{3}$
}

\begin{abstract}
Prospective memory, the ability to remember to execute an intended action at the appropriate moment in the future, is frequently assessed with standardized questionnaires. Prospective-memory abilities strongly depend on the different strategies people use to remember their intentions. In this study, we introduce the short version of the Metacognitive Prospective Memory Inventory (MPMI-s) that allows for a quick assessment of individual differences in self-reported prospective-memory abilities as well as in the use of mnemonic strategies (e.g., intention rehearsal) and external memory aids (e.g., calendars). Based on data from two waves of the GESIS Iongitudinal panel, we provide evidence that this novel questionnaire offers reliable and valid measures of prospective-memory abilities as well as of internal and external strategy use. As the panel sample is representative of the German population, we are further able to provide reference data that allow evaluating individual PM ability and strategy-use scores obtained with the MPMI-s.
\end{abstract}

Keywords: Prospective memory, Metamemory, Memory strategies, Questionnaire, Prospection

\section{Introduction}

Prospective memory (PM) refers to the ability to remember an intention at the appropriate moment in the future (Cohen \& Hicks, 2017). Typical everyday examples of PM tasks are remembering to take a cake out of the oven after $20 \mathrm{~min}$, remembering to buy a birthday present for a significant other, or remembering to take prescription pills after breakfast. From these examples, it is obvious that PM failures can have negative personal consequences, from a burnt cake or missing present ruining a birthday party to severe health issues from forgetting to take one's medicine. PM not only plays an important role in our daily lives but also in work environments (Dismukes, 2012) and for neurological and clinical disorders (cf. Raskin, 2018). PM deficits are associated with several disabling clinical disorders, such as (mild) cognitive impairments, schizophrenia, and

\footnotetext{
* Correspondence: jan.rummel@psychologie.uni-heidelberg.de ${ }^{1}$ Department of Psychology, Heidelberg University, Hauptstrasse 47-51, 69117 Heidelberg, Germany

Full list of author information is available at the end of the article
}

Parkinson's and Alzheimer's disease (Costa, Carlesimo, \& Caltagirone, 2012; Farina, Young, Tabet, \& Rusted, 2013; Zhou et al., 2017). Therefore, brief screening tools for PM impairments are of crucial importance. To this end, we present a 22-item questionnaire that allows to not only reliably asses self-perceived PM abilities but also use of strategies that may influence PM abilities in daily life. We will show that the short version of our newly developed Metacognitive Prospective Memory Inventory (MPMI-s) has good psychometric properties. We will also test for its convergent and discriminant validity by investigating whether the MPMI-s scales are, as shown for previous PM ability questionnaires, moderately related to conscientiousness and only weakly to other personality variables (Uttl \& Kibreab, 2011). We will further investigate to which extent the MPMI-s scales predict everyday planning behavior. Finally, we will provide reference data for the MPMI-s based on a large representative German sample.

The cognitive underpinnings of PM have been studied extensively within specifically devised laboratory tasks 
(see Cohen \& Hicks, 2017, for a recent overview). Additionally, standardized objective (performance-based) tests are available to assess individual differences in PM abilities (Raskin, 2009; Wilson et al., 2005). However, the use of these tasks in the diagnosis of clinically relevant PM deficits can be hampered by practical limitations such as rather extensive administration times. Critically, such tasks include artificial experimenter-imposed intentions and thus performance on these tasks may have little relation to performance on self-imposed everyday PM tasks. Indeed, there are striking differences between the performance in laboratory/experimenter-generated and naturalistic/self-imposed PM settings (Arnold \& Bayen, 2019; Bailey, Henry, Rendell, Phillips, \& Kliegel, 2010; Schnitzspahn et al., 2016). Thus, although some have questioned the validity of self-reported everyday PM abilities based on its non-correlation with laboratory PM performance (Uttl \& Kibreab, 2011), self-reports of PMgiven that they can be reliably measured-can provide crucial insights beyond artificial laboratory PM tasks. Indeed, there is good evidence for the clinical relevance of self-perceived memory abilities, which predict conversion to dementia in older adults without objectively detectable memory deficits (Mitchell, Beaumont, Ferguson, Yadegarfar, \& Stubbs, 2014).

A few questionnaires to assess perceived everyday PM abilities have been developed previously, such as the Prospective Memory Questionnaire (PMQ; Hannon, Adams, Harrington, FriesDias, \& Gipson, 1995), the Comprehensive Assessment of Prospective Memory (CAPM; Chau, Lee, Fleming, Roche, \& Shum, 2007), or the Prospective and Retrospective Memory Questionnaire (PRMQ; Crawford, Smith, Maylor, Della Sala, \& Logie, 2003; Smith, Della Sala, Logie, \& Maylor, 2000). However, the PMQ and the CAPM comprise 52 and 39 items, respectively. In many test situations, it is not feasible to use such extensive scales (Rammstedt \& Beierlein, 2014; Stanton, Sinar, Balzer, \& Smith, 2002). Indeed, the most frequently used PM questionnaire is the PRMQ, which comprises only eight PM ability items (complemented with eight retrospective-memory-ability items). This is also the only questionnaire for which normative data is available. However, the PRMQ, as well as the other PM questionnaires, exclusively rely on items that assess PM failures and are thus prone to acquiescence biases (Danner, Aichholzer, \& Rammstedt, 2015; Danner \& Rammstedt, 2016). Further, laboratory and everyday PM performances strongly depend on the use of mnemonic strategies, such as intention rehearsal, imagery, etc., as well as of external memory aids, such as calendars, todo lists, etc. (e.g.,Gilbert, 2015; Penningroth \& Scott, 2013; Shelton et al., 2016). Notably, this is particularly true for groups with PM impairments when performing naturalistic tasks, such as older adults who need to remember to make phone calls (Maylor, 1990) or patients with brain injuries who need to keep track of their activities (McDonald et al., 2011). Thus, we deem it important to assess the frequency with which people use such strategies alongside PM abilities because they (a) allow for a better interpretation of perceived PM abilities (e.g., is PM ability normal given the strategies used or are people already compensating deficits via extensive strategy use?) and because they (b) may identify means for interventions (e.g., could more external aids be used to avoid PM failures?).

To this end, we recently developed and tested a novel questionnaire specifically designed to assess perceived everyday PM abilities and PM-strategy use: the Metacognitive Prospective Memory Inventory (Rummel, Kuhlmann, \& Danner: A questionnaire for the asssessment of perceived prospective memory abilities and strategy use: The metacognitive prospective memory inventory (MPMI), in preparation). The original 44-item version of the MPMI comprises three scales for the assessment of PM abilities and PM-strategy use in everyday life, with strategies being further differentiated into internal (i.e., cognitive) and external (i.e., memory-aid) strategies. For the present MPMI short version, we selected those eight items of each scale that (a) covered a wide range of everyday PM situations and strategies, (b) loaded highest on their respective scale and not on the other scales, and (c) were rated as most content valid by two PM experts. Also, half of the PM-ability-scale items are reverse-keyed such that item-wording effects-and, among them, acquiescence biases-can be controlled for (Billiet \& McClendon, 2000; Weijters, Baumgartner, \& Schillewaert, 2013). The MPMI-s was included in two GESIS panel waves allowing us not only to investigate its factor structure and reliability, but also to derive general population norms. Furthermore, we present evidence for the scale's validity by replicating well-established relations to personality measures (i.e., conscientiousness; Cuttler \& Graf, 2007; Uttl \& Kibreab, 2011) and by additionally showing that perceived PM abilities relate to vacation planning in everyday life.

\section{Methods \\ Participants}

Participants were part of the GESIS panel, a probabilitybased, longitudinal, mixed mode access panel for the academic community featuring a sample representative of the German adult population (GESIS, 2018). The MPMI-s was administered in waves bc with $N=4069$ participants and bf with $N=3857$ (i.e., approx. 95\% of the original bc-wave participants). In wave bc (bf), the sample featured 52\% (52\%) females, a mean age of $M=$ 47.11, $S D=14.32(M=47.44, S D=14.21)$, and an age range from 19 to 71 years. A total of $46 \%$ (46\%) of the 
participants had a high school degree eligible for attending a university (German Allgemeine-/ Fachhochschulreife), 53\% (53\%) a high school degree not eligible for university entrance (German Realschul-/ Hauptschulabschluss), and 1\% (1\%) did not hold a school degree. All participants answered the MPMI-s alongside several other questionnaires.

\section{Measures \\ Metacognitive Prospective Memory Inventory short version (MPMI-s)}

The English item translations of the MPMI-s are presented in Table 1. The original German items are provided as Additional file 1. The MPMI-s consists of three scales with eight items each. Items were selected from the MPMI long version without modification. The Prospective Memory Ability (PMA) scale measures how people experience their PM abilities (e.g., "I am able to remind myself of phone calls I need to make, such as calling a friend on his or her birthday."). The items of this scale are formulated in a way so that it is obvious that they refer to memory abilities and not memory strategies (i.e., remind oneself rather than being reminded by another person or a device). Half of the items referred to prospective remembering, the other half to prospective forgetting. So, for half of the items, higher scores indicate better PM abilities, for the other half, higher scores indicate worse PM abilities. The latter

Table 1 Standardized factor loadings (CFA) of all items

\begin{tabular}{|c|c|c|c|c|}
\hline \multirow{3}{*}{$\begin{array}{l}\text { Item } \\
\text { PMA 1: I forget to cancel contracts on time, like trial subscriptions for newspapers. }\end{array}$} & \multicolumn{4}{|c|}{ Std. factor loadings } \\
\hline & \multicolumn{2}{|c|}{ Wave bc } & \multicolumn{2}{|c|}{ Wave bf } \\
\hline & -0.48 & $0.40^{\dagger}$ & -0.54 & $0.33^{\dagger}$ \\
\hline $\begin{array}{l}\text { PMA 2: I remember to run errands that need to be completed within a specific timeframe, like picking up my } \\
\text { laundry from the dry cleaner before it closes. }\end{array}$ & 0.49 & $0.30^{+}$ & 0.48 & $0.29^{+}$ \\
\hline $\begin{array}{l}\text { PMA 3: If I've borrowed something from someone for a while, I remember to give it back to that person the } \\
\text { next time we see each other. }\end{array}$ & 0.60 & $0.33^{+}$ & 0.56 & $0.32^{+}$ \\
\hline PMA 4: I forget to call a friend again after I could not reach him or her on the first try. & -0.32 & $0.36^{+}$ & -0.36 & $0.32^{+}$ \\
\hline PMA 5: I receive overdue notifications because I forget to pay bills on time. & -0.42 & $0.44^{\dagger}$ & -0.45 & $0.39^{+}$ \\
\hline PMA 6: I am able to remind myself of phone calls I need to make, such as calling a friend on his or her birthday. & 0.61 & $0.31^{\dagger}$ & 0.62 & $0.30^{\dagger}$ \\
\hline PMA 7: I remember my appointments which are coming up in a few days without writing them down. & 0.55 & $0.33^{\dagger}$ & 0.56 & $0.31^{\dagger}$ \\
\hline PMA 8: I do not send e-mails or letters on time, even when I wrote myself a reminder to do so. & -0.50 & $0.41^{\dagger}$ & -0.55 & $0.37^{\dagger}$ \\
\hline $\begin{array}{l}\text { PMSi 1: Even when I'm busy doing other things, I deliberately try to keep unfinished tasks in mind so that I do } \\
\text { not forget them. }\end{array}$ & 0.56 & & 0.59 & \\
\hline PMSi 2: In the morning, I go through the day's tasks in my head so that I do not forget to remember something. & 0.65 & & 0.66 & \\
\hline $\begin{array}{l}\text { PMSi 3: When I have to complete steps in a specific order, such as when I am baking, I visualize the sequence of } \\
\text { steps before starting. }\end{array}$ & 0.57 & & 0.58 & \\
\hline $\begin{array}{l}\text { PMSi 4: After completing a task, I check once again whether I took care of everything, like turning off the stove } \\
\text { after cooking. }\end{array}$ & 0.49 & & 0.47 & \\
\hline PMSi 5: In my mind, I make a list of things that I still have to complete. & 0.67 & & 0.70 & \\
\hline PMSi 6: I think of my to-do list while I am busy doing something else, like washing dishes or working out. & 0.67 & & 0.71 & \\
\hline $\begin{array}{l}\text { PMSi 7: Before I go shopping, I picture where the products I need are located in the store, so that I do not forget } \\
\text { to pick them up when I walk through the aisles. }\end{array}$ & 0.51 & & 0.50 & \\
\hline PMSe 1: I write myself a to-do list to remind me of things that I still need to accomplish. & 0.75 & & 0.78 & \\
\hline PMSe 2: I write shopping lists. & 0.58 & & 0.64 & \\
\hline $\begin{array}{l}\text { PMSe 3: When I have to take something with me the next morning, like a letter or a library book, I put it in my } \\
\text { bag the evening before so that I will not forget it the next day. }\end{array}$ & 0.48 & & 0.49 & \\
\hline PMSe 4: I keep a calendar with all of my appointments. & 0.51 & & 0.53 & \\
\hline PMSe 5: To help me remember to do things, I stick "Post-It "notes in obvious places. & 0.61 & & 0.60 & \\
\hline $\begin{array}{l}\text { PMSe 6: I put things in prominent places so that I'm reminded of tasks I need to do (for example, putting a full } \\
\text { trash bag in front of the door so I do not forget to take it out). }\end{array}$ & 0.55 & & 0.54 & \\
\hline $\begin{array}{l}\text { PMSe 7: For things that I need to do on a regular basis, I plan to do them at the same time each day (for example, } \\
\text { always taking my medication in the evening before brushing my teeth). }\end{array}$ & 0.40 & & 0.38 & \\
\hline
\end{tabular}

PMA prospective memory abilities, PMSi prospective memory strategies: internal, $P M S e$ prospective memory strategies: external; wave names indicate the respective GESIS panel waves; the following fit indices refer to wave bc (bf): $R M S E A_{\mathrm{PMA}}=0.063(0.066), C \mathrm{I}_{\mathrm{PMA}}=0.949(0.945), S R M R_{\mathrm{PMA}}=0.033(0.033), R M S E A_{\mathrm{PMSi}}=$ $0.078(0.079), C F I_{\mathrm{PMSi}}=0.944(0.948), S R M R_{\mathrm{PMSi}}=0.034(0.035), R M S E A_{\mathrm{PMSe}}=0.084(0.078), C F I_{\mathrm{PMSe}}=0.926(0.941), S R M R_{\mathrm{PMSe}}=0.039(0.035) ; N=4069(3857) ;{ }^{\dagger}{ }^{i t e m}$ loadings on a latent wording-effect factor 
items should usually be reverse-coded so that higher PMA scores always reflect better PM abilities. Because we intended to control for wording effects in the present study, however, we did not reverse-code these items for the reported analysis but only for the reference data. The PMSi scale assesses the frequency with which people use internal PM strategies to better remember their intentions (e.g., "In the morning, I go through the day's tasks in my head so that I don't forget to remember something."). Higher PMSi scores always indicate more frequent strategy use. The PMSe scale measures how frequently people use external PM strategies such as memory aids or preparatory actions, to better remember their intentions (e.g., "I write myself a to-do list to remind me of things that I still need to accomplish"). Again, higher PMSe scores indicate more frequent strategy use. ${ }^{1}$ For all items, the same 5-point Likert response scale is used with categories being labeled $1=$ rarely, 2 = rather rarely, $3=$ sometimes, $4=$ rather often, and $5=$ often.

\section{Big-Five Personality Inventory short version (BFI-2S)}

The German version of the BFI-2S (Rammstedt, Danner, Soto, \& John, 2018; Soto \& John, 2017) was used to assess the personality domains Extraversion, Agreeableness, Conscientiousness, Negative Emotionality (Neuroticism), and Open-Mindedness (Openness) with six items each. In the present sample, this version showed a good reliability for all scales, $0.65 \geq \alpha \geq 0.79$.

\section{Vacation planning}

As part of one wave, the GESIS panel participants were asked several questions about their next vacation. Four questions investigated which aspects of their upcoming vacation trips participants had already planned at the time of assessment. These questions always started with "Which things did you already plan for your holiday trip?" and then referred to one particular planning aspect (i.e., arrival, accommodation, food, and activities during vacation). Participants answered them using a simple yes-no response format.

\section{Data collection}

Data collection was completed as part of three different data collection waves of the GESIS longitudinal panel (GESIS, 2018). That is, the MPMI-s was assessed in waves bc (June to August 2014) and bf (December 2014 to February 2015), the BFI-2S in wave ec (June to August 2017), and vacation planning in wave bc (June to August 2014).

\section{Results}

The GESIS panel data is publically available. All analysis codes are provided as Additional file 2.

\section{Factorial structure}

Based on previous research (Rummel, Kuhlmann, \& Danner: A questionnaire for the asssessment of perceived prospective memory abilities and strategy use: The metacognitive prospective memory inventory (MPMI), in preparation), we hypothesized that items should form three different factors, that is, a PM ability (PMA), an internal PM strategy use (PMSi), and an external PM strategy use (PMSe) factor, that should be positively but moderately correlated with each other. A confirmatory factor analysis for a three-factor solution fitted the MPMI-s data from both data collection waves well, RMSEA $\leq 0.066$, CFI $\geq 0.945$, SRMR $\leq 0.033$. In this model, we also controlled for wording effects (including acquiescence) by specifying a second factor with positive loadings for both reversed and non-reversed items (Billiet \& McClendon, 2000; Maydeu-Olivares \& Coffman, 2006). Item-factor loadings and separate fit-indices for each factor for both assessments are presented in Table 1. As expected, PMA correlated moderately with PMSi, $r=$ 0.17, and PMSe, $r=0.21$; the correlation between PMSi and PMSe was higher, $r=0.69$. Taken together, the questionnaire factor structure from the original MPMI was replicated with the short version.

\section{Reliability}

To assess the MPMI-s' reliability within both assessment waves, we calculated McDonald's Omega and Cronbach's Alpha for each scale. Results, which are displayed in Table 2, indicate good reliability for all scales and measurement points $(\omega \geq 0.76, \alpha \geq 0.70)$. Retest correlations between the data obtained in the first (wave bc) and the second (wave bf) assessment further indicated that the manifest test scores were relatively stable across the 6month assessment interval ( $r \geq 0.64$, see Table 2$)$.

\section{Validity}

The BFI-2S domains were modeled as latent variables using exploratory structural equation models (Asparouhov \& Muthen, 2009) including a random intercept as wording/acquiescence factor (Aichholzer, 2014; Danner et al., 2015). We assessed latent correlations between all three MPMI-s scales and the five personality domains of

Table 2 Reliability estimates for all MPMI-s scales

\begin{tabular}{lllll}
\hline & & PMA & PMSi & PMSe \\
\hline McDonald's Omega & Wave bc & 0.78 & 0.79 & 0.76 \\
& Wave bf & 0.78 & 0.80 & 0.78 \\
Cronbach's Alpha & Wave bc & 0.70 & 0.78 & 0.75 \\
& Wave bf & 0.72 & 0.80 & 0.77 \\
Retest correlation & & 0.64 & 0.67 & 0.73 \\
\hline
\end{tabular}

PMA prospective memory abilities, $P M S$ S prospective memory strategies: internal, PMSe prospective memory strategies: external; $N=2996-4069$ 
Table 3 Latent correlations between MPMI-s scales and external criteria

\begin{tabular}{llll}
\hline Criterion & PMA & PMSi & PMSe \\
\hline Extraversion & 0.04 & $0.07^{*}$ & $0.06^{*}$ \\
Agreeableness & $0.15^{* * *}$ & $0.05^{*}$ & $0.10^{* * *}$ \\
Conscientiousness & $0.41^{* * *}$ & $0.21^{* * *}$ & $0.18^{* * *}$ \\
Neg. Emotionality & $-0.07^{* * *}$ & $0.15^{* * *}$ & $0.21^{* * *}$ \\
Open-Mindedness & $0.12^{* * *}$ & $0.11^{* * *}$ & $0.15^{* * *}$ \\
Vacation Planning & $0.15^{* * *}$ & $0.08^{* * *}$ & $0.07^{* *}$ \\
Age & $0.10^{* *}$ & $0.04^{*}$ & $0.07^{* *}$ \\
Gender & $0.12^{* * *}$ & $0.11^{* * *}$ & $0.25^{* * *}$ \\
Education & $0.14^{* * *}$ & -0.01 & $0.14^{* * *}$ \\
\hline
\end{tabular}

PMA prospective memory abilities, $P M S$ i prospective memory strategies: internal, PMSe prospective memory strategies: external; $R M S E A=0.038, C F I=$ $0.854, S R M R=0.041$; MPMI-s data from wave bf and BFI-2S data from wave ec were used; $N=4170 ;{ }^{*} p<0.05 ;{ }^{* *} p<0.01 ;{ }^{* * *} p<0.001$

the BFI-2S. As evident from Table 3, due to the large sample size, almost all correlations between the MPMI-s scales and personality domains reached conventional levels of significance. Therefore, we decided to only interpret correlations of at least $r=0.10$, that is, only correlations of at least small sizes according to Cohen's conventions (Cohen, 1968). Replicating prior research, the highest correlation observed was the moderate correlation between PMA and conscientiousness $(r=0.41)$. Both strategy scales (PMSi and PMSe) were also weakly positively correlated with conscientiousness $(r=0.21$ and $r=0.18$ ), suggesting that conscientious people invest more cognitive as well as preparation effort to avoid forgetting of intentions. We further found small positive correlations with agreeableness for both PMA $(r=0.15)$ and PMSe $(r=0.10)$. Unexpectedly, we observed similarly weakly positive correlations between negative emotionality and the two strategy scales $(r=0.15$ and $r=$ 0.21 ) as well as between all three PM scales and openmindedness $(0.11 \leq r \leq 0.15)$. Finally, as expected, PMA was positively related to vacation planning $(r=0.15)$.

\section{Age and gender differences}

As evident from Table 3, there was some evidence for small age-related differences on the (manifest) PMA scale and for gender differences on all three scales. Tests of measurement invariance (e.g., Chen, 2007) were conducted for these demographic variables (see Table 4 for the results).

For the PMA scale, measurement invariance tests comparing age groups (up to 30 years $=0 ; 31-40$ years $=1 ; 41-$ 50 years $=2 ; 51-60$ years $=3$; 61 years and older $=4$ ) were ambiguous. That is, some tests favored scalar invariance but others only metric or configural invariance, suggesting that age groups should be compared only within structural equation models accounting for age-group differences in
Table 4 Measurement invariance tests

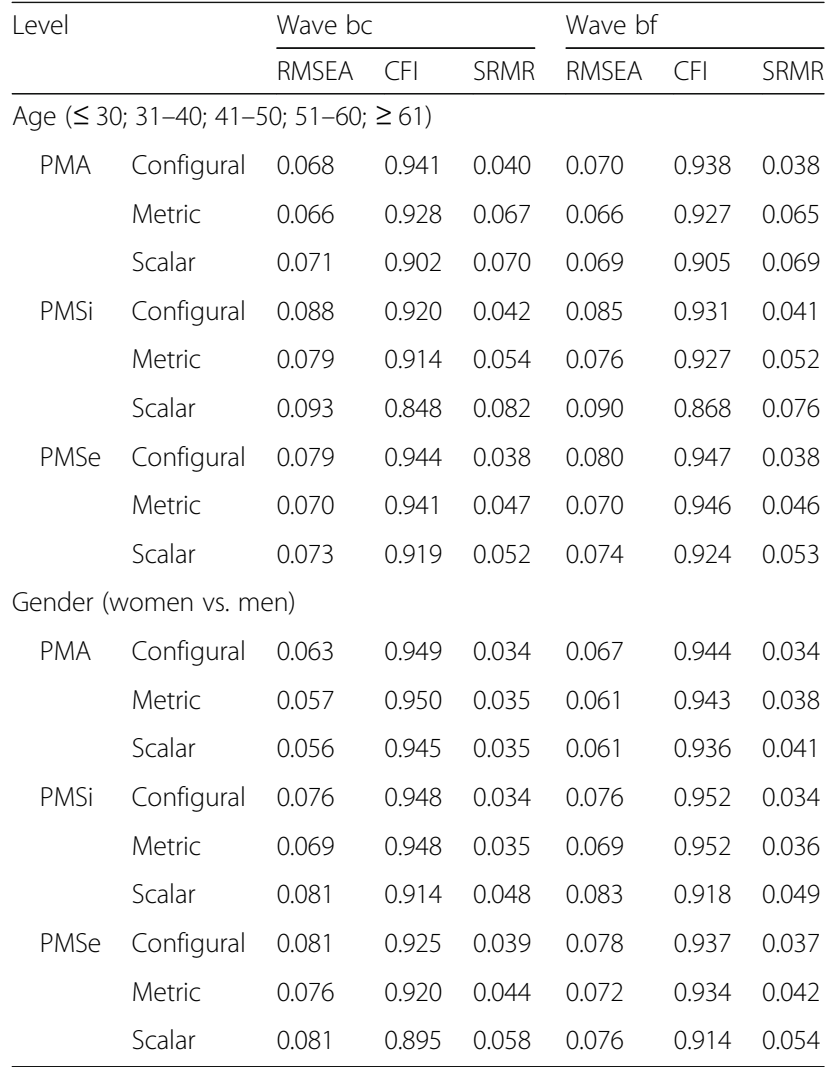

PMA prospective memory abilities, PMSi prospective memory strategies: internal, PMSe prospective memory strategies: external; MPMI-s data from waves bc and bf was used; $N=3523-4069$

item loadings and item intercepts. The tests further suggest scalar invariance between women and men (males = 1 ; females $=2$ ), implying that manifest PMA scores can be compared between women and men.

For the PMSi and the PMSe scales, measurement invariance test results for age groups again did not consistently favor a certain level of invariance, suggesting that age groups should be compared within structural equation models accounting for age-group differences in item loadings and item intercepts, only. Test results further indicated metric invariance between women and men, suggesting that differences between women and men should be investigated with structural equation models accounting for gender differences in item intercepts.

\section{Reference data}

Reference data separated by age and gender for all three scales are provided as Additional file 3. As the GESIS panel provides a sample that is representative of the German population, the reference data can be used as normative data for the interpretation of individual test scores. Because all PM scales showed some indication of age-group related variance and the PM strategy scales also varied with gender, we recommend using age- 
specific reference data for the interpretation of all test scores and gender-specific reference data for the interpretation of PM strategy scores.

\section{Discussion}

PM abilities are crucial for mastering our daily work and life activities (Dismukes, 2012) and PM deficits accompany several clinical disorders (Raskin, 2018). Therefore, the brief and reliable assessment of individual differences in PM is of interest for both psychology researchers and (clinical) practitioners. Furthermore, the assessment of PM strategies is important both for a better interpretation of reported PM abilities and for identifying means for PM improvements. The presented short version of the MPMI allows for a relatively quick and reliable assessment of internal and external PM-strategy use in addition to the assessment of self-reported PM abilities. A further advantage of our PM ability scale is that it allows to control for wording effects and particularly acquiescence bias (Weijters et al., 2013), because it features negatively and positively formulated items (i.e., items that refer to prospective remembering and items that refer to prospective forgetting). In the present investigation, we confirmed the three-factor structure of the original longer version. Despite their brevity, all scales of the short version showed good reliabilities and tests scores were sufficiently stable over 6 months.

Furthermore, we found some evidence for the short version's validity: replicating prior research with the PRMQ, PM abilities correlated moderately with conscientiousness (Cuttler \& Graf, 2007; Uttl \& Kibreab, 2011) and, to a weaker extent, with agreeableness. Uttl and Kibreab (2011) reported a similar correlational pattern, but for objective PM measures, only. The positive correlation of our PM ability scale with agreeableness may be due to the fact that at least some of the everyday PM scenarios used in the newly developed items have an obvious social component to it (e.g., remembering to call a friend on their birthday, see Table 1). We further observed a weakly positive correlation between PM abilities and open-mindedness, which seems reasonable, as openmindedness has been shown to relate to cognitive abilities (Ziegler, Danay, Heene, Asendorpf, \& Bühner, 2012) . The small but reliable correlation of PM abilities with the vacation-planning index further corroborates the scale's construct and criterion validity in everyday life.

To our knowledge, this is the first inventory to include both internal and external strategies of PM. The two strategy factors support the previously made theoretical distinction between internal and external PM strategies (Maylor, 1990; Penningroth \& Scott, 2013). As expected, both strategy factors are positively related to reported PM abilities. Their negligible correlations with the vacation planning measure are not surprising given that the vacation planning measure assessed completed plans (i.e., having booked an accommodation) rather than the strategic process of planning. Interestingly, more conscientious people seem to not only perceive their PM abilities as better but also seem to engage more strategies to prevent prospective forgetting. Furthermore, it appears that people scoring higher on negative emotionality generally use more PM strategies (internal or external), maybe to buffer their fears of forgetting to execute important intentions. Again, we observed weakly positive correlations between the external strategy scale and agreeableness as well as between both strategy scales and open-mindedness. As suggested for the PM ability scale, the former might be due to the social aspects of many everyday intentions and the latter to the wellknown link between open-mindedness and general cognitive abilities. In sum, we found good evidence for convergent validity of all three scales of the novel PM questionnaire (i.e., small to moderate correlations between conscientiousness and all PM scales). Somewhat unexpectedly, several (weak) correlations with other personality factors were also observed, however, suggesting that reported PM abilities and strategy use are not completely independent of people's levels of openmindedness, agreeableness, and emotionality. Intuitively, these relationships make sense within the nomological network of the Big-5 personality factors. However, as these relations were not observed in previous (less well powered) studies (Uttl \& Kibreab, 2011), they require further replication.

Although PM performance in objective performancebased PM laboratory tasks has been shown to decline with (old) age (Kliegel, Jager, \& Phillips, 2008), neither perceived PM abilities nor PM strategy-use varied much with age in the present study. Although this finding may in part be caused by the rather low upper age limit of 71 in the present sample, it replicates previous results of no age-related differences in reported PM abilities obtained with the PRMQ (Crawford et al., 2003). For one, this can be explained by older adults rating their memory in comparison to their peers on such questionnaires (Rabbitt, Maylor, Mcinnes, Bent, \& Moore, 1995). Further notable, it has been shown that age-related PM deficits also do not manifest themselves in naturalistic PM tasks that sometimes even produce age-related PM benefits (Schnitzspahn, Ihle, Henry, Rendell, \& Kliegel, 2011). The absence of age-related differences in perceived PM abilities thus may be reflective of a factual absence of age-related declines in real-life PM tasks.

In line with previous research using the PRMQ (Crawford et al., 2003; Uttl \& Kibreab, 2011), we did not observe gender differences in perceived PM abilities. However, we observed substantial gender-related differences in internal and external strategy use, indicating that women tend to 
use certain strategies (e.g., mental intention rehearsal, writing to-do lists) more frequently than men. This is in line with previous research that also reported a more frequent use of memory aids in women than in men (Uttl \& Kibreab, 2011). As the gender-related strategy-use differences seem to be reliable, it is advisable to take them into account when interpreting individual differences in this domain and chose reference data accordingly.

\section{Conclusion}

Taken together, the short version of the MPMI has been proven a reliable and valid instrument for the investigation of PM abilities and PM-strategy use. We hope that the MPMI-s and the reference data from the GESIS longitudinal panel will be useful for researchers who are interested in investigating individual differences in perceived PM abilities or strategy use as well as practitioners, for example in work, clinical, or rehabilitation contexts, who are interested in the comprehensive yet quick assessment of perceived PM-ability and strategyuse deficits.

\section{Endnotes}

${ }^{1}$ Items of both strategy scales were always positively formulated because, unlike the ability items, negatively formulated strategy items would have required double negotiations that we intentionally avoided because they are difficult to understand.

\section{Additional files}

Additional file 1: German MPMI-s items and their English translations. (PDF $130 \mathrm{~kb}$ )

Additional file 2: Mplus codes for all analyses. (TXT $28 \mathrm{~kb}$ )

Additional file 3: Reference data based on GESIS panel wave bc. (PDF $211 \mathrm{~kb}$ )

\section{Authors' contributions}

$J R$ and BGK developed the study idea, and DD provided critical feedback. DD conducted all analyses and JR checked them. JR drafted the manuscript and BGK and DD provided critical feedback. The final version was approved by all authors.

\section{Funding}

This research was not supported by any external funding source.

\section{Availability of data and materials}

The GESIS panel data is publically available. The questionnaire items and analysis codes are provided as Additional files 1 and 2 .

\section{Competing interests}

The authors declare that they have no competing interests.

\section{Author details}

'Department of Psychology, Heidelberg University, Hauptstrasse 47-51, 69117 Heidelberg, Germany. '2Department of Psychological Assessment \& Training, University of Applied Labour Studies, Mannheim, Germany. ${ }^{3}$ Department of Psychology, School of Social Sciences, University of Mannheim, Mannheim, Germany.
Received: 3 December 2018 Accepted: 26 May 2019

Published online: 21 June 2019

\section{References}

Aichholzer, J. (2014). Random intercept efa of personality scales. Journal of Research in Personality, 53, 1-4. https://doi.org/10.1016/j.jrp.2014.07.001.

Arnold, N. R., \& Bayen, U. J. (2019). Prospective memory: Comparing self- and proxy-reports with cognitive modeling of task performance. Journal of Applied Research in Memory and Cognition. Advanced online publication. https://doi.org/10.1016/j.jarmac.2019.04.001.

Asparouhov, T., \& Muthen, B. (2009). Exploratory structural equation modeling. Structural Equation Modeling, 16, 397-438. https://doi.org/10.1080/ 10705510903008204

Bailey, P. E., Henry, J. D., Rendell, P. G., Phillips, L. H., \& Kliegel, M. (2010). Dismantling the "age-prospective memory paradox": The classic laboratory paradigm simulated in a naturalistic setting. The Quarterly Journal of Experimental Psychology, 63, 646-652. https://doi.org/10.1080/ 17470210903521797

Billiet, J. B., \& McClendon, M. J. (2000). Modeling acquiescence in measurement models for two balanced sets of items. Structural Equation Modeling, 7, 608628. https://doi.org/10.1207/S15328007SEM0704_5.

Chau, L. T., Lee, J. B., Fleming, J., Roche, N., \& Shum, D. (2007). Reliability and normative data for the Comprehensive Assessment of Prospective Memory (CAPM). Neuropsychological Rehabilitation, 17, 707-722. https://doi.org/10. 1080/09602010600923926.

Chen, F. F. (2007). Sensitivity of goodness of fit indexes to lack of measurement invariance. Structural Equation Modeling, 14, 464-504. https://doi.org/10.1080/ 10705510701301834.

Cohen, A. L., \& Hicks, J. L. (2017). Prospective memory: Remembering to remember, remembering to forget. New York: Springer.

Cohen, J. (1968). Statistical power analysis for the behavioral sciences (Vol. 2). New Jersey: Lawrence Erlbaum Associates.

Costa, A., Carlesimo, G. A., \& Caltagirone, C. (2012). Prospective memory functioning: A new area of investigation in the clinical neuropsychology and rehabilitation of Parkinson's disease and mild cognitive impairment. Review of evidence. Neurological Sciences, 33, 965-972. https://doi.org/10.1007/ s10072-012-0935-y.

Crawford, J. R., Smith, G., Maylor, E. A., Della Sala, S., \& Logie, R. H. (2003). The Prospective and Retrospective Memory Questionnaire (PRMQ): Normative data and latent structure in a large non-clinical sample. Memory, 11, 261-275. https://doi.org/10.1080/09658210244000027.

Cuttler, C., \& Graf, P. (2007). Personality predicts prospective memory task performance: An adult lifespan study. Scandinavian Journal of Psychology, 48, 215-231. https://doi.org/10.1111/j.1467-9450.2007.00570.x.

Danner, D., Aichholzer, J., \& Rammstedt, B. (2015). Acquiescence in personality questionnaires: Relevance, domain specificity, and stability. Journal of Research in Personality, 57, 119-130. https://doi.org/10.1016/j.jrp.2015.05.004.

Danner, D., \& Rammstedt, B. (2016). Facets of acquiescence: Agreeing with negations is not the same as accepting inconsistency. Journal of Research in Personality, 65, 120-129. https://doi.org/10.1016/j.jrp.2016.10.010.

Dismukes, R. K. (2012). Prospective memory in workplace and everyday situations. Current Directions in Psychological Science, 21, 215-220. https://doi.org/10. $1177 / 0963721412447621$.

Farina, N., Young, J., Tabet, N., \& Rusted, J. (2013). Prospective memory in Alzheimer-type dementia: Exploring prospective memory performance in an age-stratified sample. Journal of Clinical and Experimental Neuropsychology, 35, 983-992. https://doi.org/10.1080/13803395.2013.844772.

GESIS. (2018). Gesis panel - standard edition (Publication no. 10.4232/1.13158). from ZA5665

Gilbert, S. J. (2015). Strategic offloading of delayed intentions into the external environment. The Quarterly Journal of Experimental Psychology, 68, 971-992. https://doi.org/10.1080/17470218.2014.972963.

Hannon, R., Adams, P., Harrington, S., FriesDias, C., \& Gipson, M. T. (1995). Effects of brain injury and age on prospective memory self-rating and performance. Rehabilitation Psychology, 40, 289-298. https://doi.org/10. 1037/0090-5550.40.4.289.

Kliegel, M., Jager, T., \& Phillips, L. H. (2008). Adult age differences in event-based prospective memory: A meta-analysis on the role of focal versus nonfocal cues. Psycholology and Aging, 23, 203-208. https://doi.org/10.1037/0882-7974. 23.1.203 
Maydeu-Olivares, A., \& Coffman, D. L. (2006). Random intercept item factor analysis. Psychological Methods, 11, 344-362. https://doi.org/10.1037/1082 989X.11.4.344.

Maylor, E. A. (1990). Age and prospective memory. The Quarterly Journal of Experimental Psychology, 42, 471-493.

McDonald, A., Haslam, C., Yates, P., Gurr, B., Leeder, G., \& Sayers, A. (2011). Google calendar: A new memory aid to compensate for prospective memory deficits following acquired brain injury. Neuropsychological Rehabilitation, 21, 784-807. https://doi.org/10.1080/09602011.2011.598405

Mitchell, A. J., Beaumont, H., Ferguson, D., Yadegarfar, M., \& Stubbs, B. (2014). Risk of dementia and mild cognitive impairment in older people with subjective memory complaints: Meta-analysis. Acta Psychiatrica Scandinavica, 130, 439451. https://doi.org/10.1111/acps.12336

Penningroth, S. L., \& Scott, W. D. (2013). Task importance effects on prospective memory strategy use. Applied Cognitive Psychology, 27, 655-662. https://doi. org/10.1002/acp.2945.

Rabbitt, P., Maylor, E., Mcinnes, L., Bent, N., \& Moore, B. (1995). What goods can self-assessment questionnaires deliver for cognitive gerontology. Applied Cognitive Psychology, 9, 127-152. https://doi.org/10.1002/acp.2350090709.

Rammstedt, B., \& Beierlein, C. (2014). Can't we make it any shorter? The limits of personality assessment and ways to overcome them. Journal of Individual Differences, 35, 212-220. https://doi.org/10.1027/1614-0001/a000141.

Rammstedt, B., Danner, D., Soto, C. J., \& John, O. P. (2018). Validation of the short and extra-short forms of the Big Five Inventory-2 (BFI-2) and Their German Adaptations. European Journal of Psychological Assessment. Advanced online publication. https://doi.org/10.1027/1015-5759/a000481.

Raskin, S. A. (2009). Memory for intentions screening test: Psychometric properties and clinical evidence. Brain Impairment, 10, 23-33. https://doi.org/ 10.1375/brim.10.1.23.

Raskin, S. A. (2018). Prospective memory in clinical populations. Clinical Neuropsychologist, 32, 741-747. https://doi.org/10.1080/13854046.2018. 1484519.

Schnitzspahn, K. M., Ihle, A., Henry, J. D., Rendell, P. G., \& Kliegel, M. (2011). The age-prospective memory paradox: An exploration of possible mechanisms. International Psychogeriatrics, 23, 583-592. https://doi.org/10.1017/ S1041610210001651

Schnitzspahn, K. M., Scholz, U., Ballhausen, N., Hering, A., Ihle, A., Lagner, P., \& Kliegel, M. (2016). Age differences in prospective memory for everyday life intentions: A diary approach. Memory, 24, 444-454. https://doi.org/10.1080/ 09658211.2015 .1018276

Shelton, J. T., Lee, J. H., Scullin, M. K., Rose, N. S., Rendell, P. G., \& McDaniel, M. A. (2016). Improving prospective memory in healthy older adults and individuals with very mild Alzheimer's disease. Journal of the American Geriatrics Society, 64, 1307-1312. https://doi.org/10.1111/jgs.14134.

Smith, G., Della Sala, S., Logie, R. H., \& Maylor, E. A. (2000). Prospective and retrospective memory in normal ageing and dementia: A questionnaire study. Memory, 8, 311-321.

Soto, C. J., \& John, O. P. (2017). The next big five inventory (bfi-2): Developing and assessing a hierarchical model with 15 facets to enhance bandwidth, fidelity, and predictive power. Journal of Personality and Social Psychology, 113, 117-143. https://doi.org/10.1037/pspp0000096.

Stanton, J. M., Sinar, E. F., Balzer, W. K., \& Smith, P. C. (2002). Issues and strategies for reducing the length of self-report scales. Personnel Psychology, 55, 167194. https://doi.org/10.1111/j.1744-6570.2002.tb00108.x.

Uttl, B., \& Kibreab, M. (2011). Self-report measures of prospective memory are reliable but not valid. Canadian Journal of Experimental Psychology, 65, 57-68. https://doi.org/10.1037/a0022843.

Weijters, B., Baumgartner, H., \& Schillewaert, N. (2013). Reversed item bias: An integrative model. Psychological Methods, 18, 320-334. https://doi.org/10. 1037/a0032121.

Wilson, B. A., Emslie, H., Foley, J., Shiel, A., Watson, P., Hawkins, K., et al. (2005). The Cambridge prospective memory test. London: Harcourt-Assessment.

Zhou, F. C., Wang, C. Y., Ungvari, G. S., Ng, C. H., Zhou, Y., Zhang, L., et al. (2017). Longitudinal changes in prospective memory and their clinical correlates at 1-year follow-up in first-episode schizophrenia. PLoS One, 12. https://doi.org/ 10.1371/journal.pone.0172114.

Ziegler, M., Danay, E., Heene, M., Asendorpf, J., \& Bühner, M. (2012). Openness, fluid intelligence, and crystallized intelligence: Toward an integrative model. Journal of Personality, 46, 173-183. https://doi.org/10.1016/j.jrp.2012.01.002.

\section{Publisher's Note}

Springer Nature remains neutral with regard to jurisdictional claims in published maps and institutional affiliations.
Ready to submit your research? Choose BMC and benefit from:

- fast, convenient online submission

- thorough peer review by experienced researchers in your field

- rapid publication on acceptance

- support for research data, including large and complex data types

- gold Open Access which fosters wider collaboration and increased citations

- maximum visibility for your research: over $100 \mathrm{M}$ website views per year

At $\mathrm{BMC}$, research is always in progress.

Learn more biomedcentral.com/submissions 